\title{
Política de Assistência Social: as direções da matricialidade sociofamiliar e do trabalho social com famílias
}

Social assistance policy: social work with families and directions of familiar social matrix

\author{
Izabel Hérika Matias Cronemberger* \\ Solange Maria Teixeirat"
}

\begin{abstract}
Resumo:
A família tem sido tomada como referência nas políticas sociais, em especial na de assistência social, o que tem reatualizado as demandas e expectativas em relação ao trabalho social dirigido a elas. Todavia, a direção dessa inserção da família na política pode se apresentar bastante variada e tensionada entre projetos: o familista, que a toma como um canal natural de proteção social a ser acionado pelas políticas sociais; o protetivo, fundado na proteção social pública, ou ainda um terceiro que conjuga e inter-relaciona os dois projetos. $O$ objetivo deste artigo é problematizar as diferentes direções da matricialidade sociofamiliar na política de assistência social e suas repercussões no trabalho social.
\end{abstract}

Palavras-Chave: Política de assistência social. Serviço social. Família.

\begin{abstract}
:
The family has been taken as a reference in social policies, in particular on social assistance, which has updated the demands and expectations of the social work directed to them. However, the direction of that family involvement in politics can present quite varied and tensioned between projects: the familism, that takes as a natural channel of social protection to be triggered by social policies; the protective, based on public social protection, or one third combines and interrelates the two projects. The aim of this paper is to discuss the different directions of familiar social matrix in social assistance policy and its impact in social work.
\end{abstract}

Keywords: Social assistance policy. Social work. Family.

\section{Introdução}

A legislação da PNAS/2004 orienta-se pela "primazia de atenção às famílias e seus membros a partir do seu território de vivência, com prioridades àqueles com registro de

\footnotetext{
- Assistente Social, Mestre em Políticas Públicas e docente da Faculdade Santo Agostinho. E-mail: izabel herika@hotmail.com

** UFPI/Departamento de Serviço Social e Programa de Pós-Graduação em Políticas Públicas. Doutorado em Políticas Públicas. E-mail: solangemteixeira@hotmail.com
} 
fragilidades, vulnerabilidades e presença de vitimização de seus membros" (BRASIL, 2005, p. 90).

Assim, tem a PNAS centralidade nas famílias, em especial naquelas tidas como vulneráveis e em situação de risco, e abrangem novas dimensões conceituais e um campo de ação para além das emergenciais, como as caracterizadas de prevenção, além das de riscos sociais.

Essas inovações implicam mudanças nos processos de trabalhos e no desenvolvimento de novas competências e saberes. As normatizações provocam, em geral, expectativas e demandas por uma nova lógica de gestão financeira, de recursos humanos, de estruturas físicas e inovações no trabalho social com famílias.

O objetivo deste artigo é problematizar a política de assistência social, em especial, identificar as diferentes direções da matricialidade sociofamiliar e suas repercussões no trabalho social com famílias nos CRAS e CREAS, a partir da análise política dessa política, do seu desenho, mediante legislação e normas operacionais e técnicas do MDS sobre o trabalho social com famílias.

\section{Matricialidade Sociofamiliar: quais as direções possíveis?}

A matricialidade sociofamiliar é fundante na Política de Assistência Social (PAS), tanto que a PNAS/2004 define, entre suas diretrizes, a "centralidade na família para concepção e implementação dos benefícios, serviços, programas e projetos" (BRASIL, 2005, p. 33), e entre seus objetivos "assegurar que as ações no âmbito da assistência social tenham centralidade na família e garantam a convivência familiar e comunitária" (BRASIL, 2005, p. 33). Isso indica uma das direções da centralidade na família, na perspectiva de sujeito de direitos, como matriz de organização dos serviços da rede socioassistencial. Ou seja, as demandas e necessidades familiares são prioritárias e conduzirão a oferta de serviços, programas e projetos.

Quando se visualiza a rede de proteção social, geralmente de organizações sociais não governamentais e governamentais; a reduzida oferta de serviços de atenção, cuidado e proteção social às famílias pelo poder público, exceto a estrutura de porta de entrada da rede CRAS e CREAS; a reduzida capacidade e atendimento das organizações de assistência 
social face às demandas, pode-se inferir que a família se enquadra no que é ofertado e não o contrário.

Outra direção da matricialidade sociofamiliar, expressa no desenho da política, e que vai de encontro à primeira, é quando busca potencializar a função protetiva da família, como um dos mecanismos de prevenção dos problemas sociais. Essa direção está expressa, ao afirmar:

i) a família é o núcleo social básico de acolhida, convívio, autonomia, sustentabilidade e protagonismo social; ii) a defesa do direito à convivência familiar, na proteção de Assistência Social, supera o conceito de família como unidade econômica, mera referência de cálculo de rendimento per capita e a entende como núcleo afetivo, vinculado por laços consangüíneos, de aliança ou afinidade, que circunscrevem obrigações recíprocas e mútuas, organizadas em torno de relações de geração e de gênero; iii) a família deve ser apoiada e ter acesso a condições para responder ao seu papel no sustento, na guarda e na educação de suas crianças e adolescentes, bem como na proteção de seus idosos e portadores de deficiência; iv) o fortalecimento de possibilidades de convívio, educação e proteção social na própria família não restringe as responsabilidades públicas de proteção social para com os indivíduos e a sociedade (BRASIL, 2005, p. 90).

Está explícito o paradigma que para a família proteger ela precisa ser protegida, ou, ao contrário, a família é merecedora de proteção porque promove proteção, logo o direito à proteção não é incondicional, mas exige contrapartidas que implicam o alargamento de suas funções e a manutenção de outras, como socialização, educação, assistência e cuidados.

Ressalta-se que ao mesmo tempo que se notam avanços na extensão do conceito de família pela percepção das diversas situações em que se encontra, e das necessidades que apresenta, veem-se nos princípios versados nuanças de contradições, pois se a família é reconhecida e retomada como lócus primeiro de sustentabilidade e responsabilidades sobre o próprio sucesso ou insucesso, e esse protagonismo depende da sua capacidade natural para alcançar a harmonização, mesmo num contexto de transformações advindas da sociedade contemporânea, são visíveis as expectativas de que essa possa gerar proteção social, integração independente de seu estado de vulnerabilidade.

Assim, a PNAS/2004 reconhece a família como o cerne norteador da proteção social, inserida no conjunto de transformações societárias contemporâneas nos aspectos econômicos, sociais, de hábitos e costumes e avanço tecnológico. 


\begin{abstract}
Essas transformações, que envolvem aspectos positivos e negativos, desencadearam um processo de fragilização dos vínculos familiares e comunitários e tornaram as famílias mais vulneráveis. A vulnerabilidade à pobreza está relacionada não apenas aos fatores da conjuntura econômica e das qualificações específicas dos indivíduos, mas também às tipologias ou arranjos familiares e aos ciclos de vida das famílias. Portanto, as condições de vida de cada indivíduo dependem menos de sua situação específica que daquela que caracteriza sua família. No entanto, percebe-se que na sociedade brasileira, dada as desigualdades características de sua estrutura social, o grau de vulnerabilidade vem aumentando e com isso aumenta a exigência das famílias desenvolverem complexas estratégias de relações entre seus membros para sobreviverem (BRASIL, 2005, p. 42).
\end{abstract}

Fica evidente o reconhecimento das transformações das famílias em razão das mudanças sociais, com a ampliação de fragilidades e vulnerabilidades e alterações nos formatos, entre outras. Aponta-se ainda como avanço que o conceito de família se alarga, superando a referência de tempo e lugar e indo além dos arranjos consanguíneos e estruturas físicas. "Pode-se dizer que estamos diante de uma família quando encontramos um conjunto de pessoas que se acham unidas por laços consanguíneos, afetivos e ou de solidariedade" (BRASIL, 2005, p. 42).

Tal alargamento do conceito de família possibilita perceber as diversas situações a que estão submetidas, e os novos arranjos que compõe, passando a ser reconhecida como unidade familiar e lócus de intervenção da PAS, se houver necessidade. A PNAS/2004 traz significativos avanços, como o reconhecimento da família como núcleo central merecedor de proteção estatal, pois "a realidade tem dado sinais cada vez mais evidentes de processos de penalização e desproteção das famílias brasileiras" (BRASIL, 2005, p. 42).

$\mathrm{Na}$ verdade, as mudanças atingem apenas o conceito de família, mas não suas funções e responsabilidade, que devem ser mantidas independentemente dos formatos, condições de vida e vicissitudes da convivência. Como destaca Mioto (2006), são novas propostas com velhos princípios, ou, como diz Pereira (2006), a exigência das mesmas funções da família como há cinquenta anos é uma visão idílica, uma vez que nem a situação de vulnerabilidade é suficiente para o Estado protegê-la.

Os princípios reafirmam que para receber proteção a família necessita proteger seus membros, o que deve ser potencializado, desenvolvido e incentivado, como se o problema fosse a incapacidade dela de exercer suas funções, e não a realidade estruturalmente 
desigual e excludente, que de inúmeras formas nela se reflete. E quando não há condições para proteção? E quando essa capacidade é limitada pela pobreza e luta pela sobrevivência material? Os serviços destinados à família aparecem no subterfúgio do apoio, o que é preocupante se esse se reduz a ações paliativas e superficiais ou a serviços socioeducativos que visam potencializar a protetividade e não se efetiva no viés do direito à proteção social e à inclusão social na rede de serviços, prioritariamente pública, comprometendo, de forma significativa, a sobrevivência do grupo e de seus vínculos.

O alerta de Bronfenbrenner (1995, p. 120) requer atenção, uma vez que "se a família não funciona, não é porque ela é composta por pessoas de má índole que não se preocupam, ou cujo amor pelos filhos não é suficientemente grande. É porque as circunstâncias não o permitem".

Dessa feita, é possível visualizar a família sendo responsabilizada e culpabilizada pelos infortúnios de que é acometida, em vez de ter seus direitos garantidos. Para sustentar essa reflexão, Ribeiro (2001, p. 35) argumenta que:

[...] está equivocado quem pensa que a criança de rua está nessa condição porque não tem uma família. Todas elas têm. O problema reside no fato de que, em geral, sua família está em crise, sem estrutura para resolver seus problemas. Isso não significa que, necessariamente, seus pais sejam incompetentes para criar seus filhos. A questão ultrapassa a insensatez. A família da criança em situação de rua compõe uma parcela da sociedade que não recebe apoio do Estado porque este não implementa políticas públicas efetivas para dar o suporte que as famílias necessitam [...].

Assim, a família sem proteção social direta e efetiva do Estado em quantidade e qualidade para atender às suas necessidades e a exclusão do mercado de trabalho, ou a inserção precária, ampliam as situações de vulnerabilidade e riscos sociais. É que a família sem proteção sente-se impossibilitada de atender às necessidades básicas (água, saúde, alimentação, moradia, educação, renda e cidadania) de seus membros e tornam-se vítimas da injustiça social tendo seus direitos violados. Por conseguinte, ocorrem, entre outros fatos, a ida dos filhos para a rua, o uso de substâncias psicoativas, o abandono da escola para ajudar no orçamento familiar, o esgarçamento dos vínculos afetivos e sociais, em decorrência da angustiante luta pela sobrevivência, e as rupturas dos laços conjugais por não poderem cumprir os papéis socialmente determinados para o pai e a mãe. 
Acredita-se que o caminho para a prevenção dos problemas sociais numa sociedade capitalista é a priorização da proteção pública, com oferta de benefícios monetários generosos e serviços de inclusão social em primeira instância para toda a família, o que implica o reconhecimento de direitos, a garantia da dignidade humana e o convívio comunitário e familiar. No entanto, em que pesem as incoerências, é perceptível na NOB/SUAS (BRASIL, 2005) o direcionamento organizacional e funcional à proteção social das famílias em situações de vulnerabilidades, embora limitada pelos princípios contraditórios, a realidade institucional da oferta de serviços e as condições de trabalho profissional.

\section{A Matricialidade Sociofamiliar materializada nos Programas de Proteção Básica e Especial}

Com já assinalado, há na PNAS (2004) e NOB/SUAS (2005) uma inovação significativa na concepção de família, que se define como um grupo unido por laços conjugais, filiais ou fraternais/afetivos. Essa novidade contribui para romper com os estigmas construídos, reconhecer a inexistência de um modelo idealizado de família e admitir a sua capacidade plural de compor arranjos. Mas é conservadora em termos das expectativas em relação à família e suas funções, contradição que se expressa na condução do trabalho social com famílias.

\footnotetext{
Na proteção básica, o trabalho com famílias deve considerar novas referências para a compreensão dos diferentes arranjos familiares..., partindo do suposto de que são funções básicas das famílias: prover a proteção e a socialização dos seus membros; constituir-se como referências morais, de vínculos afetivos e sociais; de identidade grupal, além de ser mediadora das relações dos seus membros com outras instituições sociais e com o Estado (BRASIL, 2005, p. 35).
}

O principal serviço de proteção social básica do SUAS, que materializa a centralidade na família, é o PAIF, ofertado por meio dos serviços socioassistenciais, socioeducativos e de convivência, e os projetos de preparação para a inclusão produtiva voltados às famílias, membros e indivíduos, conforme as necessidades identificadas no território. O PAIF é realizado exclusivamente pelo poder público nos CRAS e tem por perspectiva "o fortalecimento de vínculos familiares e comunitários, o direito à proteção social básica e 
ampliação da capacidade de proteção social e prevenção de risco no território de abrangência do CRAS" (BRASIL, 2005, p. 15).

O PAIF, criado em 18 de abril de 2004 (Portaria no 78) pelo MDS aprimorou a proposta do Plano Nacional de Atendimento Integrado à Família (PNAIF), implantado, em 2003, pelo governo federal. Em 19 de maio de 2004, o PAIF tornou-se "ação continuada da Assistência Social", passando a integrar a rede financiada pelo governo federal (Decreto 5.085/2004), saindo de programa para serviço.

Dentre os pressupostos do PAIF, destaca-se:

1- a família como modelo idealizado, inexiste, mas sim famílias que resultam de uma pluralidade de arranjos e rearranjos, estabelecidos pelos integrantes;

2- $\quad$ a família deve ser apoiada pela proteção social de assistência social e ter acesso a condições para responder ao dever de sustento, guarda e educação de suas crianças, adolescentes e jovens à proteção dos seus membros em vulnerabilidade, principalmente idosos e pessoas com deficiência;

3- o fortalecimento de possibilidades de convívio, educação e proteção social da família não restringe as responsabilidades públicas dessa proteção para com os indivíduos e a sociedade (BRASIL, 2006, p. 27).

Aparecem, no texto legal, as mesmas contradições da PAS porque o princípio é o mesmo, com avanços e recuos. Avanços porque se rompe com a ideia de modelo idealizado de família nuclear, e recuo porque, no segundo pressuposto, impõem-se limites e condicionalidades a um sujeito para receber proteção social. Oferece-se apoio e exige-se que a família realize ações no seu âmbito restrito, atribuídas genericamente a todos os tipos familiares, independentemente das condições de vida e das formas de convivência. Isso se dá apesar da tentativa de não desresponsabilizar o poder público.

Na proteção social especial presente no SUAS, o CREAS é a unidade pública e estatal de abrangência municipal ou regional que oferta, obrigatoriamente, o PAEFI. De acordo com a Tipificação Nacional de Serviços Socioassistenciais, a Proteção Social Especial de Média Complexidade inclui o PAEFI, o Serviço Especializado em Abordagem Social, o Serviço de Proteção Social a Adolescentes em Cumprimento de Medida Socioeducativa de Liberdade Assistida (LA) e de Prestação de Serviços à Comunidade (PSC), Serviço de Proteção Social Especial para Pessoas com Deficiência, Idosas e suas Famílias e o Serviço Especializado para Pessoas em Situação de Rua. 
Compete ao CREAS (BRASIL, 2009) ofertar e referenciar serviços especializados de caráter continuado para famílias e indivíduos em situação de risco pessoal e social, por violação de direitos e por violência, expressa em maus-tratos, negligência, abandono, discriminações, entre outras. A busca é a de resgatar vínculos familiares e sociais rompidos, apoiando-se a construção ou reconstrução de projetos pessoais e sociais. Na verdade, a centralidade da família no CREAS tem como objeto:

[...] compreender, em um determinado contexto, como se constroem e se expressam as relações familiares entre seus membros. Essa perspectiva não visa responsabilizar a família e seus componentes no tocante às vicissitudes que vivenciam no seu cotidiano, mas contextualizar a situação vivida e recolocar o papel do Estado como provedor de direitos por meio das políticas sociais, fornecendo instrumentos de apoio e sustentação necessários para a proteção social das famílias (BRASIL, 2011, p. 33).

Isso significa um avanço pelo reconhecimento de que as vicissitudes e infortúnios que acometem as famílias em situação de risco social e pessoal não são de responsabilidade delas, o que recoloca o papel do Estado como provedor de direitos e responsável pela proteção social. O PAEFI, por exemplo, oferta serviços de apoio, orientação e acompanhamento a famílias com um ou mais de seus membros em situação de ameaça e violação de direitos. Esses serviços, ofertados nos CREAS, têm como objetivos:

i) O fortalecimento da função protetiva da família; ii) A construção de possibilidades de mudança e transformação em padrões de relacionamento familiares e comunitários com violação de direitos; iii) A potencialização dos recursos para a superação da situação vivenciada e a reconstrução de relacionamentos familiares, comunitários e com o contexto social, ou construção de novas referências, quando for o caso; iv) O empoderamento e a autonomia; v)O exercício do protagonismo e da participação social; vi) O acesso das famílias e indivíduos a direitos socioassistenciais e à rede de proteção social; vii) A prevenção de agravamentos e da institucionalização (BRASIL, 2011, p. 51).

São, por sua vez, objetivos do PAEFI:

i) Contribuir para o fortalecimento da família no desempenho de sua função protetiva; ii) Processar a inclusão das famílias no sistema de proteção social e nos serviços públicos, conforme as necessidades; iii)Contribuir para restaurar e preservar a integridade e as condições de autonomia dos usuários; iv)Contribuir para romper com padrões violadores de direitos no interior da família; v)Contribuir para a reparação de danos e da incidência de violação de direitos; vi)Prevenir a reincidência de violações de direitos (BRASIL, 2009, p. 20). 
Os objetivos do CREAS e do PAEFI também demarcam peculiaridades de retrocessos na condução de uma política que deveria ser desfamilizante quando reafirma a necessidade de fortalecimento e potencialização da função protetiva da família, mesmo com vínculos já violados. É como se a solução para o problema fosse a falta de proteção social exercida pelas famílias ou seu uso inadequado, tentando-se ajustá-la nos intramuros familiares. Ora, embora a família seja um dos agentes de violação de direitos, ela o faz por desconhecimento, traços culturais patriarcais, pelo uso de álcool e outras drogas, associados ao desemprego, à precariedade de condições de vida, e à falta de expectativas sociais.

O primeiro objetivo é, pois, contraditório em relação aos demais, mas avançado quando reconhece a necessidade do empoderamento e autonomia das famílias, o exercício da participação social, articulação com serviços socioassistenciais de proteção básica, a busca de reparação dos danos e a prevenção da reincidência das violações de direitos. A proteção social especializada deve se dirigir à família que, enquanto espaço contraditório e ambíguo, pode constituir um dos espaços de violação de direitos, submissões e violências. Essa situação requer trabalho educativo de reabilitação para a convivência familiar, mas sem cair em culpabilizações estéreis. Ao Estado cabe prover serviços especializados de tratamento das situações provocadoras de violação e incluir os membros familiares naqueles que, de fato, alterem-lhes a condição de risco social e carências extremas, buscando construir relações sociais e familiares menos assimétricas, e mais horizontais, fundadas no respeito mútuo e na cultura de direitos.

Essa duvidosa proteção social à família, reconhecida de um lado como direito e, de outro, como significante parceria, exige contrapartidas do grupo, ampliando-se as responsabilidades familiares ao invés de independentizar os indivíduos dos seus cuidados e recursos, como seria próprio de uma política desfamiliarizante. Isso dá sustentáculo à ideia de que a proteção social se desvia da rota da garantia do direito quando, para ser concretizada, requer parceria.

A ausência ou a limitada rede de atenção socioassistencial, sua filantropização e precarização, e a retomada da família como parte essencial dela, com funções potencializadas para prevenir os riscos sociais, padecem de um acentuado 
conservadorismo, considerando que famílias pobres acumulam vulnerabilidades e fragilidades e precisam de serviços inclusivos e socioeducativos emancipatórios, os únicos capazes de oferecer à política social uma perspectiva preventiva e de investimento social.

A centralidade da família na política social, em especial na assistência social, ocorre num cenário marcado, de um lado, pelos movimentos sociais que lutavam pela desinstitucionalização das práticas assistenciais e, de outro, pelo avanço das propostas neoliberais de redução do Estado e o retorno das demandas de proteção social para canais naturais como família e mercado. As influências neoliberais e a manutenção da intervenção do Estado como cada vez mais focalizada geraram um novo modelo de proteção social, que envolve o mix público/privado ou o pluralismo de bem-estar social, reafirmado na noção de rede socioassistêncial.

Não significa dizer que o modelo da PNAS e da NOB/SUAS seja conservador e neoliberal, até porque, é uma tentativa de efetivação da PAS como política pública. Entretanto, elas absorvem, no seu desenho, a nova cultura ou o consenso no modo de fazer política social, envolvendo o mix público/privado na composição das redes. O privado é também a própria família, as comunidades e organizações não governamentais, tomadas como parceiros, sendo função do poder público coordenar, financiar e potencializar essa rede, na qual se espera, por parte da família, a utilização de seus recursos e sua solidariedade e o cumprimento das funções clássicas de sustento, socialização, educação e cuidados, o que amplia o trabalho das mulheres, historicamente responsabilizadas por esses serviços.

Ressalta-se que muitas das novas formas de organização familiar, como as famílias chefiadas por mulheres, as monoparentais, ou a de um único provedor em situação de trabalho precário e irregular acumulam pobreza, vulnerabilidades e dificuldades de cuidados aos membros dependentes, sendo-lhes impossível atuar de forma preventiva. Responsabilizá-las ainda mais e potencializar-lhe funções clássicas só aumentaria o sentimento de culpa por não poder cumpri-las, conforme as expectativas sociais.

A crítica mais contundente à afirmação da família como referência das políticas públicas, na atualidade, está associada à regressão da participação do Estado na provisão de bem-estar e a consequente privatização das respostas às refrações da questão social, tomadas agora como "casos de famílias". Ou seja, desvia-se da rota da garantia dos direitos 
sociais por meio de políticas públicas de caráter universal e entra-se na rota da focalização das políticas públicas, nos segmentos mais pauperizados da população, em parceria com as organizações não governamentais de assistência social. Nesse sentido, fortalece-se significativamente o privado, como instância de provisão de bem-estar, apostando nas organizações da sociedade civil e da família como provedoras de serviços.

Ressalte-se que não se envereda, neste estudo, por uma discussão da desresponsabilização da família de seu papel e funções protetivas, mas diz-se da ampliação da astúcia de que esses são modificáveis, intercambiáveis e negociados na trama familiar e afetado pelas mudanças sociais. Por esta razão, a proteção social primária deve permanecer no âmbito das relações informais guiadas pelo amor, solidariedade e cooperação, exceto quando destrutivas e geradoras de violação de direitos. Na verdade, a função de uma política pública é oferecer serviços de proteção básica e especial que sejam preventivos ou especializados e trabalho socioeducativo emancipatório, não apostando, potencializando e fortalecendo essas funções da família como forma de prevenir e tratar os problemas sociais.

Como destacado, a família protege, regida pelos princípios de afetividade, cooperação e solidariedade, pois é uma unidade especializada de vínculos e relações de pertencimento que não precisa ser formalizada, administrada ou responsabilizada pelo Estado. As restrições formais imputadas à família são formas de responsabilizá-la e punir a que não cumpra os ditames impostos pelas legislações.

É preciso destacar que não se defende, neste estudo, a forma clássica de institucionalização, mas o convívio familiar e comunitário, a ser garantido pelo Estado como direito dos cidadãos. Deve haver, assim, alternativas de intervenção social descentralizadas, com clara definição de responsabilidades entre os entes governamentais e participação e controle social da sociedade, além de políticas que garantam benefícios e serviços para os membros familiares como mecanismo direto de assegurar o direito à convivência familiar e comunitária.

Neste estudo, também não se defende um Estado onipresente e onipotente, embora seja o único que, com sua intervenção, possa garantir direitos sociais, pois a família vulnerável tem dificuldade para garantir proteção e cuidar por falta de recursos materiais e humanos. O mercado, por ser excludente, só protege os que podem pagar pelos serviços 
e apesar de o Estado não responder adequadamente às desigualdades sociais, deve ele, pelo papel e função de garantidor de direitos sociais, garantir a reprodução social dos trabalhadores e minorias, embora essa cobertura dependa da correção de forças, das lutas de classes e movimentos sociais.

Em relação à direção da centralidade na família, a PNAS/2004 ora a reconhece como sujeito de direitos e sujeita à proteção social, ora a toma como agente de proteção social natural e informal, que tem de ser potencializada com novas competências para cuidar melhor de seus integrantes e minimizar a necessidade de serviços públicos, reduzindo-se as demandas ao Estado. Mesmo dito isso, o SUAS representa uma clara possibilidade de avanço na sua organização e no seu legítimo reconhecimento como política de seguridade social, ainda que existam diversas questões a serem discutidas e repensadas, como a matricialidade sociofamiliar, que passa a ter papel de destaque no âmbito do SUAS e merece ser melhor decifrada, debatida e redefinida.

O próprio esboço da incorporação do PAIF e PAEFI como serviço, caracterizando, assim, ações de natureza continuada e com financiamento regulado é um avanço e demanda novas perspectivas de trabalho social com famílias, numa dimensão de efetivação de direitos e numa lógica de emancipação e protagonismo social.

\section{O Trabalho social com famílias no âmbito do SUAS: novas perspectivas?}

O trabalho social com famílias (TSF), na proteção social básica e especializada da assistência social, tem como principal objetivo a potencialização das funções protetivas da família.

A aposta é que fortalecendo as funções protetivas da família, por meio de ações como acolhida e oficinas, evite-se riscos advindos de problemas que existem pelo fato de não desempenhar adequadamente suas funções, passando a resolução e a prevenção pela responsabilização e cumprimento de deveres familiares. Daí o trabalho social com centralidade na família, no âmbito dos CREAS visa:

[...] ao fortalecimento da sua função de proteção e atenção a seus membros, prevenindo, mediando e fortalecendo condições para a superação de conflitos. Essa perspectiva é fundamental para prevenir a recorrência e/ou agravamento de processos que gerem e/ou acentuem situações de violência, abandono, 
negligência ou qualquer outro tipo de situação de risco pessoal e social por violação de direitos (BRASIL, 2011, p. 34).

Apesar dessa limitação, que decorre das contradições presentes no texto normativo e que se expressam nas orientações do trabalho social, muitas mudanças ocorrem pela sua condução mais crítica.

Nas orientações técnicas, vê-se que o TSF se dá por acompanhamentos individualizados ou em grupos. Um dos objetivos, precisamente nas oficinas com famílias na esfera comunitária territorial, é o de:

[...] fomentar a reflexão sobre a importância e os meios de participação social, inclusive por meio do estímulo à participação nas atividades de planejamento do PAIF, bem como em espaços públicos de consulta popular e/ou deliberativos (comitês, conselhos, associações) para a garantia dos direitos e o exercício da cidadania. Esses objetivos contribuem para o desenvolvimento de projetos coletivos e o empoderamento da comunidade, assim como para a conquista do protagonismo e da autonomia de cada um dos membros das famílias do território (BRASIL, 2012, p. 24-25).

[...] que o trabalho social no CREAS deve ser orientado, ainda, pelo reconhecimento do protagonismo e da autonomia do usuário nas decisões e respostas às situações que vivenciam. Nesse sentido, não podem ser considerados meros objetos de intervenção, mas sujeitos autônomos e protagonistas, com possibilidades de acessar um conjunto de serviços e órgãos de defesa de direitos. Trata-se de sujeitos com direito à escuta e que devem participar ativamente da construção de projetos e decisões que possam repercutir sobre sua trajetória de vida individual e familiar (BRASIL, 2011, p. 32).

Nesse parâmetro, há possibilidades reais de um trabalho realizado na lógica do direito, com a construção de sujeitos sociais conscientes e participativos, visto por um prisma que não psicologiza ${ }^{1}$ os problemas sociais, mas alarga a percepção das situações pessoais e sociais no campo de luta pela garantia dos direitos. Por outro ângulo, tende-se a retroceder quando se reafirma nos objetivos do trabalho social com famílias, dando seguimento a uma atuação que se propõe a:

[...] estimular a socialização e a discussão de projetos de vida, a partir de potencialidades coletivamente identificadas; possibilitar a discussão sobre as situações vivenciadas pelas famílias e as diferentes formas de lidar com tais situações, por meio da reflexão sobre os direitos, os papéis desempenhados e os interesses dos membros das famílias; propiciar a melhoria da comunicação e

\footnotetext{
${ }^{1}$ As respostas aos problemas são vistas de forma particularizada e individualizada.
} 
fomentar a cooperação entre os membros das famílias (BRASIL, 2012, p. 24, grifo nosso).

[...] o desenvolvimento do trabalho social pelos Serviços do CREAS pressupõe a construção de projetos de vida e de novas possibilidades de relacionamento, com superação das situações adversas vivenciadas; a perspectiva do trabalho em rede para a atenção integral e o acesso a direitos; o desenvolvimento de potencialidades, com a ressignificação de vivências devendo nortear a elaboração do Plano de Acompanhamento Individual e/ou Familiar (BRASIL, 2011, p. 58, grifo nosso).

Isso pode significar uma motivação para que a família reflita sobre a própria realidade e construa bases para gerenciar conflitos a partir dos seus (na maioria das vezes) escassos recursos, ou reconhecer, pelo viés normatizador e disciplinador dos papéis sociais, as carências, de um ponto de vista individual e não coletivo. Contudo, mesmo dirigindo-se às questões internas da família, percebe-se a intenção de problematização das estruturas desiguais e hierarquizadas no interior das famílias e de romper com preconceitos, estereótipos e formas violentas de interação, repensando-se esses papéis.

Ressalte-se que o TSF deve inserir-se numa perspectiva dialética, que supera a visão das necessidades e saídas apenas nos intramuros domésticos, para apreendê-las como frutos da estruturação da sociedade e de suas transformações. É que as soluções passam pela autonomia das famílias via fortalecimento do coletivo na luta pela garantia de respostas do poder publico às suas necessidades, o que é reconhecido nas normatizações técnicas do MDS.

\footnotetext{
A centralidade na família no trabalho social no CREAS implica no reconhecimento da autonomia da família e de cada um de seus membros na construção de sua trajetória e projetos de vida. Nessa perspectiva, devem ser consideradas as especificidades de gênero e dos ciclos de vida dos integrantes das famílias atendidas, compreendendo suas potencialidades, necessidades humanas e peculiaridades, sob a ótica do direito assegurado ao cidadão no ordenamento jurídico brasileiro (BRASIL, 2011, p. 35).
}

Pelo exposto até aqui se pode observar que o trabalho socioeducativo com famílias ou grupos familiares e os procedimentos individuais de acolhimento, escuta qualificada, oficinas com famílias, ações comunitárias e ações particularizadas, encaminhamentos e acompanhamentos devem buscar a inserção desses sujeitos no território e na rede de segurança social, com o binômio de articulação entre o individual e o familiar inseridos num 
contexto social. É que, conforme discute Teixeira (2010b, p. 20), deve-se "ultrapassar o imediatismo de suas concepções, mas tendo como princípio que subjetividades transformadas só provocam mudanças com ações coletivas, com acesso a serviços e benefícios, ou seja, com condições objetivas".

O atendimento e acompanhamento familiar no âmbito do PAIF são definidos como "um conjunto de intervenções desenvolvidas em serviços continuados, com objetivos estabelecidos, que possibilitam à família acesso a um espaço onde possa refletir sobre sua realidade, construir novos projetos de vida e transformar suas relações - sejam elas familiares ou comunitárias" (BRASIL, 2012, p. 57). A necessidade de acompanhamento das famílias é relevante, todavia os sujeitos priorizados, a exemplo das famílias em descumprimento das condicionalidades, famílias do Plano Brasil sem Miséria e famílias do BPC de até 18 anos fora da escola e outras, representam uma seletividade, sem dizer do risco de se transformarem em objetos de normatizações e disciplinarização para que possa retornar à condição de serem merecedores dos benefícios e serviços, qual seja, exercer as funções de cuidado, socialização e guarda, além de levarem as crianças à escola, à saúde etc.

Deve haver, é certo, uma preocupação de ultrapassar a lógica do atendimento "caso a caso" ou "caso de família", que vincula a satisfação das necessidades à (in)competência individual do grupo pelo redimensionamento do trabalho com famílias na perspectiva do direito e coletivização de demandas reafirmando o caminho para a concretização da cidadania como as políticas públicas. Mas, no TSF, no âmbito da assistência social, é pura retórica, pois esses espaços, em especial os grupais, sejam de reflexão, e acesso à informação, o são também de apoio, potencialização e aquisição de saberes, e habilidades protetivas da própria família e executada por ela.

O reforço das funções protetivas é um elemento que tem perpassado o trabalho, que significa dirigir os cuidados, assistência, apoios a serem realizados pela família (em especial às mulheres), cabendo aos profissionais ensiná-las a desempenhá-los adequadamente. Esse, na verdade, é o limite concreto do trabalho social com família expresso na normatização e disciplinamento.

Todavia, são perceptíveis os avanços do TSF no CREAS, quando se destacam a importância do acesso das famílias e indivíduos aos direitos socioassistenciais, o 
reconhecimento das pluralidades da composição familiar, das diferenças e das necessidades de proteção conforme os ciclos de vida e a inclusão na rede. Ocorre, porém, retrocesso quando se enfatiza que o acesso aos diretos socioassistenciais tem em vista "o empoderamento e a potencialização de seus recursos e capacidade de proteção" (BRASIL, 2011 , p. 34). Assim, o trabalho com famílias se dirige para o que a família tem como recursos para ajudá-las a reconhecê-los e, depois, estimular seu uso e seu fortalecimento. Logo, reflete a responsabilização da família, ou seja, as ações se direcionam ao fortalecimento da função de proteção da família, como lócus primeiro de ação.

Outros objetivos mostram avanços no direcionamento do TSF no CREAS, segundo as normas de orientação técnica que defendem (BRASIL, 2011, p. 34-35) a participação social dos usuários e as intervenções nos territórios voltadas à mobilização social para a prevenção e o enfrentamento de situações de risco pessoal e social decorrentes da violação de direitos.

Conforme as normas, a participação social dos usuários constitui importante instrumento para o conhecimento e a defesa coletiva de direitos e, por conseguinte, para o exercício do protagonismo. Nessa direção, as orientações se destacam pelo viés da efetiva participação, possibilidades reais dos usuários participarem e/ou organizarem associações, movimentos sociais e populares, comissões locais, participação nas instâncias de controle social, como conselhos de direito e de políticas públicas, relevantes espaços de debate, decisão e deliberação.

Para Battini e Costa (2007), torna-se significativa a necessidade de conjugarem-se serviços e finalidades e direcionar as práticas técnico-políticas numa perspectiva de valores e princípios do campo democrático-popular.

\section{Notas para um Trabalho Social com Família numa Matriz Crítica}

Acredita-se que o TSF não deva partir de uma lógica existencial e relacional da discussão dos conflitos internos do grupo familiar, com seus recursos e as potencialidades da comunidade, do apelo moral às suas funções, mas sim direcionado ao fortalecimento das possibilidades reais de proteção da unidade familiar como sujeitos de direitos (a ser garantido pelos entes públicos) e não como objetos terapêuticos. Isso porque, no que tange 
ao TSF, urge entender que as demandas/necessidades das famílias decorrem da organização capitalista e, consequentemente, não podem ser visualizadas como problema individual ou de família.

Assim, a compreensão da questão deve ultrapassar a ótica de uma construção singular para que se perceba entrecruzada por múltiplas relações que condicionam e definem a dinâmica da família, vista para além dos vínculos de afetos e cuidados. Isso porque o campo da proteção social como garantia de direito social, deve ser de responsabilidade do Estado, ${ }^{2}$ mediante acesso a renda e ao usufruto de bens e serviços de caráter universal e de qualidade.

À luz da questão social, torna-se imperativo entender que a responsabilidade da proteção social não está restrita às famílias e que a solução do problema extrapola as suas possibilidades individuais.

Segundo Teixeira (2010a), o grande desafio para os profissionais é trabalhar, de forma dialética e articulada, assuntos internos e externos a elas, nos aspectos objetivos e subjetivos de sua vida social. Essa direção deve articular-se ao contexto de desigualdade e exclusão social, às transformações sociais e culturais e à necessidade de lutas coletivas para a conquista e garantia de direitos e o controle social das políticas públicas voltadas às suas necessidades.

O TSF, segundo reflexões de Teixeira (2010a), deve direcionar-se por uma perspectiva de ampliação do universo informacional e da oferta de serviços e recursos no âmbito das diversas políticas, de forma a buscar a inserção das pessoas e famílias na rede de segurança social garantida pelo poder público, que, em quantidade, atenda-lhes as necessidades num quadro de lutas por cidadania.

O TSF deve, conforme Mioto (2010), estruturar-se em três processos: i) os políticos organizativos, que privilegia e reconhece a família como detentora de direitos, rompendo com o sistema ideológico que a tem como responsável pela proteção social e reconhecendo

\footnotetext{
${ }^{2}$ Compreende-se o Estado como definido por Gramsci (2000, p. 331) "todo um complexo de atividades práticas e teóricas com as quais a classe dominante não só justifica e mantém seu domínio, mas consegue obter o consenso ativo dos governados", o que implica domínio e consentimento, luta por hegemonia e um Estado perpassado pela luta de classes e correlação de forças. O pacto de classes que deu origem ao Estado Social ou Welfare State nos pós-guerras é a materialização dessa concepção e o modelo de Estado, que cobre os riscos sociais de forma universal e fundado nos valores de justiça social e igualdade, é o tipo ideal ou utopia que se busca a possibilidade de efetivação de direitos sociais na ordem capitalista, o que não exclui ou elimina as desigualdades sociais, mas as minimiza e mantém em nível de civilidade.
} 
as suas necessidades imediatas, de médio e a longo prazos; ii) os de planejamento e gestão, que compreendem um conjunto de ações profissionais com foco no planejamento institucional, não para o atendimento das próprias necessidades institucionais, e sim para o atendimento das necessidades das famílias, o que requisita práticas efetivas de intersetorialidade para aliviar a carga de responsabilização familiar por cuidados; iii) os socioassistenciais, que correspondem às ações realizadas diretamente com as famílias, numa perspectiva de construção de autonomia, devendo ser entendida como possibilidades reais de engajamento ativo das famílias no contexto da participação política.

A participação política é aqui compreendida, na visão de Nogueira (2004), como canal no qual indivíduos e grupos interferem para fazer com que diferenças e interesses aconteçam num mesmo terreno, organizado por leis e instituições, e o poder se democratize e seja compartilhado. É na participação política que se consolidam, protegem e dinamizam a cidadania e os mais variados direitos humanos.

O trabalho socioeducativo é necessário, mas não deve se sustentar em uma visão fragmentada e de restrição da família, mas no viés do fortalecimento do processo organizativo e na necessidade da participação e do controle social, ou nas palavras de Teixeira (2010b, p. 19) apoiar-se em "algo que se aproxima de uma educação que visa a emancipação social". A noção de autonomia, para o alcance do objetivo do TSF não se pautará pelo viés da solução imediata das dificuldades nos intramuros da família ou dos grupos socioeducativos a quais pertença, mais antes, ainda conforme Teixeira (2010b, p. 17-18),

\footnotetext{
No desenvolvimento da capacidade de discernir as mudanças possíveis de serem realizadas no âmbito dos grupos familiares e de suas redes, daquelas que exigem o engajamento deles, organizados em coletivos, em processos sociais mais amplos para que ocorram transformações mais gerais e a efetivação de direitos. Assim, envolve capacidade de opinar, escolher, decidir e agir intencionalmente, mediante suportes oferecidos, capacidades construídas, situações refletidas, informadas, debatidas, devendo ser esses os objetivos da educação que visa à emancipação.
}

Isso corrobora com a discussão de Draibe (1990), que reflete que o objetivo da política social em relação à família não deve ser o de pressionar as pessoas para que assumam responsabilidades além de suas forças e de sua alçada, mas o de oferecer-lhes alternativas realistas de participação cidadã. Registre-se que não se desconsidera a 
solidariedade da família na construção da proteção social, com apoio, cuidados e proteção, mas se tornam essas formas primárias, que se dão no âmbito privado, incapazes de superar o ciclo da pobreza intergeracional e as vulnerabilidades sociais, daí requere-se a presença do poder público que, com rede formal de apoio, traga cuidados e assistência para materializar o direito à vida familiar e comunitária.

O TSF deve buscar democratizar as relações familiares e romper com as hierarquias, submissões, papéis diferenciados por sexo e, principalmente, levar as famílias a reconhecerem a necessidade do acesso a direitos, bens e serviços, para superarem os estados de vulnerabilidade que vivenciam. Para além dos arranjos informais de provisão social, há que se resgatar a política social pública e, com ela, as condições de sua confiabilidade e coerência, as quais se assentam no conhecimento, o mais criterioso possível, da realidade e no comprometimento com as legítimas demandas familiares contemporâneas.

Sabe-se que a família tem passado por fortes transformações, no entanto, muitas vezes o olhar está direcionado somente à sua estrutura e composição. As expectativas quanto às suas obrigações e responsabilidades permanecem inalteradas, esperando-se de todas as famílias o mesmo protótipo de funcionalidade, independentemente de suas condições econômicas, políticas, culturais e sociais. Trata-se de um arquétipo crivado por postulações tradicionalistas referentes à família ideal e ao seu papel de cuidados materno e paterno.

Nessa discussão, importam as ponderações de Fonseca (2002) sobre as mudanças na família e nos movimentos da sociedade ocorridas nos últimos anos, quando ela passa a ser vista sob outro prisma e ocupa espaços na agenda governamental e em estudos que marcam a necessidade de se lhe consolidar políticas, com a preocupação crucial de não incidir na reedição de práticas assistencialistas que a transformam em "alvo" de programas socioeducativos que as responsabilizam pela resolução de problemas vivenciados no âmbito privado (MIOTO, 2004).

Na verdade, a tendência de responsabilização da família resulta da combinação da expansão e avanço das reformas neoliberais, que impõem o enxugamento das atribuições do Estado e repassa aos movimentos sociais e à sociedade civil e comunidades deveres que não querem mais assumir. Precariza-se, assim, o TSF via serviços inócuos e desqualificados, 
aprofundando-se a situação de miséria de inúmeras famílias, num processo denominado de neofamilismo, que

[...] traduz o subjacente à tendência ideológica atual de transformar a unidade familiar em solução para a racionalidade do modelo global, reprivatizando atividades no passado tornadas públicas e trazendo a unidade doméstica-privada por definição - de volta para a sociedade em geral (DE MARTINO, 2001 apud CAMPOS; MIOTO, 2003, p. 186).

Cabe salientar que, ao longo dos anos, esses reflexos da responsabilização da família pelo cuidado de seus membros, assistindo-os, criando-os e educando-os, vêm sendo legalmente legitimado, conforme se vê no Capítulo VII, art. 227 e 229 da Constituição Federal de 1988, sem dizer do dever para com idosos (Lei $n^{\circ} 10.741 / 03$ ) e as crianças (Estatuto da Criança e Adolescente), reafirmados, sutilmente, na PAS.

Nessa perspectiva, são notórios alguns avanços da PAS principalmente na construção do TSF numa perspectiva de acesso a direitos e o incentivo à participação. Mas as contradições e ambiguidades se tornam visíveis e expressas na dimensão da potencialização das funções protetivas da família, sem deixar de atentar que, por trás de um arcabouço normativo, existe a operacionalização prática e as condições efetivas para que as bases normativas transcendam do mundo legal e se aproxime do cotidiano das famílias.

Destaque-se, ainda, que por vezes não se percebe a sobrecarga que recai sobre a família, e nem que em nome de proteção se exige mais mesmo das mais fragilizadas. Diante de tantas mudanças que atingem as famílias e das vulnerabilidades diversas que assolam as mais pobres, é possível esperar o mesmo padrão de funcionamento? Mesmo considerando as contradições que tem a família para responder satisfatoriamente às demandas advindas da proteção social? Ou as demandas e expectativas as têm tornado mais vulneráveis e fragilizadas?

\section{Considerações finais}

A análise do desenho da Política de Assistência Social e normas do MDS para o trabalho social com famílias apontam para o reforço da tendência familista ainda predominante nessa política, o que repercute diretamente no TSF. Mas como as nuanças 
da tendência protetiva também estão presentes no desenho da PNAS, isso pode impactar significativamente um redesenho do TSF, desde que seja reforçado o acesso aos serviços, logo, a inclusão social e o trabalho socioeducativo numa dimensão política do reforço ao direito e superação da cultura de subalternidade dos usuários.

Ressalte-se a expectativa, de que o TSF seja efetivamente voltado à garantia do direito, na perspectiva da proteção, emancipação e participação cidadã, e não para a transferência e acúmulo de responsabilidades sobre as famílias vulneráveis. Que se (re)acenda a luta por um Estado protetor e comprometido publicamente com as famílias e suas legítimas demandas.

\section{Referências}

BATTINI, O.; COSTA, L. C. Estado e políticas públicas: contexto sócio-histórico e assistência social. In: BATTINI, O. (Org.). SUAS: sistema único de assistência social em debate. São Paulo: Veras, 2007.

BRASIL. Ministério do Desenvolvimento Social e Combate à Fome- MDS. Política Nacional de Assistência Social (PNAS). Brasília, 2005.

. Ministério do Desenvolvimento Social e Combate à Fome - MDS. Proteção básica do sistema único de assistência social: orientações técnicas para os centros de referência de assistência social. Brasília, 2006.

. Ministério do Desenvolvimento Social e Combate à Fome- MDS. Tipificação nacional dos serviços socioassistenciais. Brasília, 2009.

Ministério do Desenvolvimento Social e Combate à Fome- MDS. Orientações técnicas: CREAS. Brasília, 2011.

Ministério do Desenvolvimento Social e Combate à Fome- MDS. Trabalho social com famílias do Serviço de Proteção e Atendimento Integral à Família: PAIF. Brasília, 2012.

BRONFENBRENNER, U. A ecologia do desenvolvimento: experimentos naturais e planejados. Porto alegre: Artes Médicas, 1995.

CAMPOS, M. S.; MIOTO, R. C. T. Política de assistência social e a posição da família na política social. SER Social, Brasília, n. 12, p. 165-190, 2003.

DRAIBE, S. M. As políticas sociais brasileiras: diagnóstico e perspectivas. In: IPEA/IPLAN. Para a década de 90: prioridades e perspectivas de políticas sociais. Brasília, 1990.

FONSECA, M. T. N. M. Famílias e políticas sociais: subsídios teóricos e metodológicos para a formulação e gestão das políticas com e para as famílias. 2002. 152 f. (Dissertação de 
Mestrado em Administração Pública) - Escola de Governo Fundação João Pinheiro, Belo Horizonte, 2002.

GRAMSCI, A. Cadernos do cárcere. Rio de Janeiro: Civilização Brasileira, 2000. v. 2.

MIOTO, R. C. T. Ações socioeducativas em programas de transferência de renda. In: WANDERLEY, M. B; OLIVEIRA, I. C. (Org.). Trabalho com famílias. São Paulo: IEE-PUC, 2004. (Textos de apoio, v. 2).

Novas propostas e velhos princípios: a assistência às famílias no contexto de programas de orientação e apoio sociofamiliar. In: SALES, M. A.; MATOS, M. C.; LEAL, M. C. (Org.) Política social, família e juventude: uma questão de direitos. São Paulo: Cortez, 2006.

Família, trabalho com famílias e serviço social. Serviço Social em Revista, Londrina, v. 12, n. 2, p. 163-176, jan./jul. 2010.

NOGUEIRA, M. A. Um estado para a sociedade civil: temas éticos e políticos da gestão democrática. São Paulo: Cortez, 2004.

PEREIRA, P. A. P. Mudanças estruturais, política social e papel da família: crítica ao pluralismo de bem-estar. In: SALES, M. A.; MATOS, M. C.; LEAL, M. C. (Org.). Política social, família e juventude: uma questão de direitos. 2. ed. São Paulo: Cortez, 2006.

RIBEIRO, M. O. A criança de/na rua tem família: uma família em crise. Desenvolvimento Humano, São Paulo, n. 11, p. 35-47, 2001.

TEIXEIRA, S. M. Trabalho interdisciplinar nos CRAS: um novo enfoque e trato à pobreza? Textos \& Contextos, Porto Alegre, v. 9, n. 2, p. 286 - 297, ago./dez, 2010a.

. Trabalho social com famílias na política de assistência social: elementos para sua reconstrução em bases críticas. Serviço Social em Revista, Londrina, v. 13, n. 1, p. 4-23, jul./dez. 2010b. 